\title{
Cartas, escravos e mulheres: três versões de um mesmo tropo
}

[ Letters, slaves and women: three versions of a same trope

\section{Rodrigo Cerqueira ${ }^{\mathrm{I}}$}

Este artigo foi financiado pela Fapesp e desenvolvido ao longo do pós-doutorado no Departamento de Sociologia da Faculdade de Filosofia, Letras e Ciências Humanas da Universidade de São Paulo (FFLCH/USP).

RESUMO - Este artigo busca analisar e explicar as modificações por que passa um mesmo tropo literário - o do escravo doméstico como portador de uma carta amorosa - em três produções ficcionais brasileiras do século XIX, a saber: Rosa (I849), de Joaquim Manuel de Macedo; O demônio familiar (1857), de José de Alencar; e, por fim, Iaiá Garcia (I878), de Machado de Assis. Argumenta-se que, ao colocar em cena o escravo doméstico como portador de uma carta amorosa, esses autores discutem, de maneiras distintas, todas historicamente determinadas, um mesmo problema social, que diz respeito às normas de autoridade senhorial e sua dissolução ao longo do século XIX. PALAVRAS-CHAVE - Ficção brasileira; tropo; Joaquim Manuel de Macedo; José de Alencar; Machado de Assis. - ABSTRACT - This paper intends to study and explain a literary trope - a domestic slave as the bearer of a love letter - and its modifications in three nineteenth-century Brazilian works, namely: Rosa (I849), by Joaquim Manuel de Macedo; O demônio familiar (I857), by José de Alencar; and, last, Iaiá Garcia (I878), by Machado de Assis. By using a slave as the bearer of a love letter, these writers discuss, in different ways, all historically determined, the same social problem, which concerns patriarchal authority and its dissolution throughout nineteenth-century. • KEYWORDS · Brazilian ficcion; trope; Joaquim Manuel de Macedo; José de Alencar; Machado de Assis.

Recebido em 6 de maio de 2016

Aprovado em 6 de setembro de 2016

CERQUEIRA, Rodrigo. Cartas, escravos e mulheres: três versões de um mesmo tropo. Revista do Instituto de Estudos Brasileiros, Brasil, n. 67, p. 8I-IoI, ago. 2017.

DOI: http://dx.doi.org/Io.II6o6/issn.23I6-90IXvo67p8I-IoI

I Universidade Federal de São Paulo (Unifesp, São Paulo, SP, Brasil). 


\section{UM CAPÍTULO DE MACEDo a TítULO DE INTRODUÇÃo}

O capítulo XI de Rosa, romance de Joaquim Manuel de Macedo publicado em I849, inicia-se com a constatação de que, na casa do pai da protagonista, Maurício, não havia nenhuma regra que regesse o horário das refeições, o que deixava o hóspede (nesse caso específico, Anastácio) "sujeito aos caprichos da bela moça”. Servido o almoço, Rosa começa suas provocações. Interrompe a leitura de Anastácio para discutir sobre o baile, assunto que sabe incomodá-lo, um homem da roça, austero, nada afeito às novas modas da corte. Contudo, se, para Anastácio, os bailes são simples demonstrações da depravação que assola a juventude, Rosa contra-argumenta, defendendo, ao contrário do que se pode imaginar, que os saraus, novidade num Rio de Janeiro no início do processo de modernização, respeitam a moral e os bons costumes. Mais correto do que a conversa às escondidas, como era praxe das mulheres de antigamente, proibidas de participar de reunião dessa natureza, é melhor que ela o faça à vista de todos: "As moças de hoje escrevem cem vezes menos cartas, do que escreviam as de outro tempo; porque dizem passeando, o que poderiam mandar dizer escrevendo"3. A resposta de Anastácio - "Mas era melhor, que não fizessem nem uma, nem outra cousa"4 - se inscreve sob o signo do autoritarismo senhorial5, que busca o controle total de todos aqueles que são seus subordinados.

O capítulo, cuja graça deriva das provocações ao tio roceiro, se encerra na mesma toada. Frente às imprecações do velho Anastácio - "tenho a educação austera do

2 MACEDO, Joaquim Manuel de. Rosa. Rio de Janeiro: H. Garnier, 2 t., s.d. [I849], p. I39, I. Embora tenha atualizado a ortografia segundo a regra vigente, mantive a pontuação de acordo com o original.

3 Ibidem, p. I47, I.

4 Ibidem.

5 Escolhi usar, ao longo do texto, o conceito de senhorial (em todas as suas variações morfológicas) em detrimento do de patriarcal, mais comum nos debates literários. Faço-o em linha com as considerações de Sidney Chalhoub, para quem patriarcalismo tem sido usado sem o devido distanciamento em relação à autoimagem produzida por essa ideologia. CHALHOUB, Sidney. Machado de Assis, historiador. São Paulo: Cia. das Letras, 2003. No seu caso, ele busca demonstrar como há uma margem de ambiguidade em situações em que parece imperar a subordinação dos dependentes, a partir da qual constrói uma visão alternativa da lógica de dominação senhorial. No meu caso, que estou trabalhando no centro mesmo dessa visão de mundo, tampouco me interessa aceitar os termos propostos pela ideologia senhorial. Trata-se, como se verá, de indicar as estratégias literárias de supressão dos pontos de contestação - a mulher e o escravo - até sua inversão machadiana. 
outro tempo, sou tenaz; eu com austeridade, e com tenacidade faria minha filha obedecer-me" - , Rosa propõe um desafio. Mandaria uma carta debaixo do nariz dele, sem que fosse descoberta. Se fosse apanhada em delito, estaria disposta a sofrer as punições, físicas inclusive, que seu tio julgasse necessárias. Em dois tempos, ela sobe ao quarto, escreve uma resposta a Juca - o protagonista masculino do romance, com quem se desentendera -, que esconde nas medidas de um sapato que furara propositalmente, e a despacha através de um escravo. E não perde tempo em contar vitória: "Meu tio, tornou a moça sorrindo-se com indizível graça; não é verdade, que na medida de uns sapatos pode-se fazer ir uma carta de amor?!!!”.

À primeira vista, a derrota do autoritarismo violento de Anastácio por uma moça afeita a uma sensibilidade mais mundana pode parecer alentador. A cena, contudo, não foi escrita com esse propósito. Logo depois de descer, atrasada para o almoço, Rosa recebe às escondidas, pelas mãos de seu pajem, Rafael, a tal carta de Juca. O fato de ter consigo uma carta amorosa no momento em que defende a moralidade mais aberta dos bailes não conta muito a seu favor, dando certa razão de ser ao obscurantismo do tio. A cena, na verdade, funciona como um condensado do romance. A questão que será trabalhada por Macedo diz respeito aos perigos trazidos por esse novo comportamento, que não leva em consideração a moral de uma autoridade tradicional, pondo em risco o funcionamento da ordem social.

Quando lido em seu contexto, Rosa ganha novas dimensões de sentido, escapando ao esquema limitado dos romances sentimentais, sem maior interesse, ao qual foi relegado. Há toda uma problemática que gira em torno do tipo mais eficaz de autoridade para lidar com um mundo em mudança percorrendo o vocabulário dos romances macedianos. O que está em jogo é o processo de reconstrução da ordem imperial, posta em xeque pelo período regencial (I83I-I840), não por acaso experienciado pelas elites como um momento anárquico. Se sua raiz histórica se encontra no processo de descentralização liberal da década de I830, a sua formulação ideológica, que é a que nos interessa aqui, consolida a ideia de que "a ordem imperial prezava-se superior à 'desordem' que lhe antecedera”. . A vitoriosa elite saquarema passa a amparar seu ritual de dominação sobre o pressuposto de que se faz necessário, mais do que nunca, uma ordem austera, intransigente, que ganha corpo e valor positivo na personagem de Anastácio, contraposta ao desregramento da sobrinha, a ser posta na linha. $\mathrm{O}$ achado literário de Macedo está na transposição de um sistema de valor conservador, roceiro, em grande medida arcaico, para dentro do enredo sentimental, estruturando-o segundo uma lógica senhorial, altamente hierárquica e autoritária, que se tornaria, na década de I850, hegemônica.

Note-se que, no capítulo que tem nos servido de introdução ao assunto desse artigo, Macedo coloca, numa mesma cena, três elementos que funcionam no sentido de desrespeito à ordem senhorial: um escravo que traz uma carta amorosa a uma moça. Macedo formaliza, assim, um tropo narrativo no qual está sintetizado um conjunto

6 MACEDO, Joaquim Manuel de. Rosa, op. cit., I47, I.

7 Ibidem, p. I5I, I.

8 ALONSO, Angela. Ideias em movimento: a geração de I870 na crise do Brasil-Império. São Paulo: Paz e Terra, 2002, p. 56. 
de ansiedades típico da elite brasileira do período, que vai da escravidão como um corruptor do lar até as formas de aliança postas em xeque por uma relação amorosa que não passe pelo crivo do senhor-proprietário. O sentido desse tropo, contudo, só pode ser estabelecido, primeiro, pelo significado social de cada um desses elementos em conjunção com o espaço e desenvolvimento no enredo, quando retornaremos a Rosa. Por fim, pretendo ainda demonstrar como um mesmo tropo pode apresentar sentidos diferentes, histórica e socialmente determinados', à medida que eles são, primeiro, reorganizados por José de Alencar e, posteriormente, subvertidos por Machado de Assis.

\section{SigNIFICADO SOCIAL DOS ELEMENTOS}

Partindo de uma dicotomia, salvo engano, trabalhada pela primeira vez por Gilberto Freyre, Sandra Lauderdale Graham apresenta o funcionamento da estrutural social brasileira a partir do seu núcleo de significado mais importante, o lar ${ }^{\mathrm{To}}$. É dentro do espaço doméstico que o senhor pode exercer sua autoridade sobre aqueles que lhe são subordinados - mulheres, escravos, dependentes -, sem maiores ingerências externas. O controle desses grupos, naturalmente, não é absoluto. Mas, segundo seus próprios esquemas, a manutenção da ordem, dentro desse mundo senhorial, está assentada na preservação daquelas hierarquias sociais, que colocam o homem branco, livre e proprietário em posições privilegiadas. E é no interior da casa (que é a ambientação por excelência dos romances urbanos do século XIX, é sempre bom lembrar) onde essa estrutura se mostrará mais coesa, cabendo a cada um dos subordinados o cumprimento de um papel social bastante preciso.

Dentro desse modelo de interpretação da sociedade brasileira oitocentista, a rua funciona como o polo oposto ao da casa. Por um lado, é o lugar aberto ao imprevisível. É bem verdade que não se pode dizer que aí as hierarquias estão embaralhadas, não se sabendo exatamente o lugar que os transeuntes ocupam no corpo social. A cor da pele, a vestimenta, os adereços são signos externos que funcionam no sentido de manter tão às claras quanto possível aquelas hierarquias ${ }^{\text {II }}$. Contudo, ainda assim, apesar de todas

9 Apesar do mal-estar que o conceito de determinação pode vir a causar em virtude de seu ranço marxista, o do pior tipo, que reduz a obra ao momento histórico em que foi produzida, roubando a agência ao escritor, resolvi mantê-lo ainda assim. Faz parte do melhor esforço da crítica cultural materialista britânica - em cuja tradição, em grande medida, este ensaio se insere - lidar com as formulações mais simplistas daquela corrente e superá-las. Nesse sentido, uso o conceito de determinação de acordo com o esforço de Raymond Williams, para quem esta deve ser entendida como limites e pressões que são historicamente postas. WILLIAMS, Raymond. Marxism and literature. Oxford: Oxford UP, I977, p. 83-90. Isso não quer dizer que o escritor não tenha liberdade de criação, mas que ela se dá dentro de um processo social e uma tradição literária já consolidada, dos quais não pode escapar com um simples gesto de voluntarismo.

Io GRAHAM, Sandra Lauderdale. House and street: the domestic world of servants and masters in nineteenth-century Rio de Janeiro. Cambridge: Cambridge UP, I988.

II FREYRE, Gilberto. Sobrados e mucambos: decadência do patriarcado e desenvolvimento do urbano. I6. ed. São Paulo: Global, 2006. 
essas estratégias, as formas de controle não podem ser tão efetivas quanto dentro do espaço doméstico. Por outro lado, a rua é onde o poder senhorial encontra limites e tem que ceder espaço - ou medir forças, na pior das hipóteses - à impessoalidade das leis. O próprio Macedo dá notícia desse embate entre a casa e a rua (entendida como autoridade geral) em suas Memórias da Rua do Ouvidor. Noticiando a chegada da família real ao Rio de Janeiro do início do século XIX, Macedo trata do edital afixado pelo intendente-geral da polícia, Paulo Fernandes Viana, no qual se determinava "a abolição das rótulas e gelosias dos sobrados" ${ }^{\text {ז2 }}$. Ainda que as razões fossem as mais legítimas dentre elas estava a higiene que uma arquitetura mais arejada traria -, Macedo ressalta que "muitas casas resistiram à reforma decretada pela civilização"ז3.

Uma perspectiva historiográfica contemporânea, de fundo thompsoniano, pode nos ajudar a pensar tanto a passagem de Macedo citada no parágrafo anterior, quanto a dicotomia entre casa e rua. Para o historiador Paulo César Garcez Marins, as reformas urbanas buscavam prescrever um tipo de arquitetura europeia, racional e iluminista, em detrimento das consolidadas ao longo do processo de colonização brasileiro, de forte herança mourisca. Era uma forma de adaptar a cidade ao seu novo patamar social, sede do Reino Unido de Portugal e Algarves, deixando para trás o atraso ao qual tinha sido submetida pelo domínio metropolitano. Note-se que a perspectiva de Macedo guarda bem essa dimensão normativa, europeia, em sintonia com o eterno propósito de colocar o país em dia com o centro do mundo. Seu corolário é a exclusão de grupos sociais marginalizados, os portadores do atraso nacional, segundo esse ponto de vista. Para esses grupos, contudo, a rótula ${ }^{\mathrm{I} 4}$ tinha uma dimensão subversiva, pois permitia, por exemplo, ao escravo fugido a proteção necessária, assim como, ao homem livre, o comércio mais das vezes ilegal. A rótula funcionava, sob o ponto de vista das classes baixas, como proteção contra a autoridade instituída ${ }^{15}$.

A perspectiva histórica de Marins é das mais importantes, pois resgata a sociabilidade dos grupos marginalizados, cuja experiência precisa ser extraída a contrapelo da documentação tradicional. Mas, ao alargar a experiência dos grupos subalternos, Marins achata a das classes altas. Entre o final da década de 1870, quando as crônicas de Macedo sobre as gelosias foram publicadas, e 1808, início do processo de legislação sobre o espaço urbano carioca, vão-se quase sete décadas.

I2 MACEDO, Joaquim Manuel de. Memórias da Rua do Ouvidor. Rio de Janeiro: Typ. Perseverança, I878, p. I34.

I3 Ibidem, p. I35.

I4 "As rótulas, treliças de madeira [...] que cobriam a quase totalidade das casas coloniais brasileiras, serviam para selar a inimizade" entre a casa e a rua, "resguardando mulheres nas residências lacradas pela tirania misógina do ciúme dos maridos e pais. Ver sem ser visto é o mote" presente em grande parte dos estudos sobre a “comunicação entre ruas e casas". MARINS, Paulo César Garcez. Através da rótula: sociedade e arquitetura no Brasil, séculos XVII a XX. São Paulo: Humanitas, 200I, p. 52.

I5 MARINS, Paulo César Garcez. Através da rótula: sociedade e arquitetura no Brasil, séculos XVII a XX. São Paulo: Humanitas, 200I. Uma crítica da dicotomia casa/rua, assim como uma leitura a contrapelo do fenômeno da rótula, pode ser encontrada em: MARINS, Paulo César Garcez. Através da rótula: sobre mediações entre casas e ruas. Cadernos CERU, São Paulo, série 2, n. 8, p. 5I-57, I997. Disponível em <http://www.revistas. usp.br/ceru/article/view/74974>. Acesso em: 26 jul. 2016. 
A consolidação da "gramática comportamental burguesa"16, que se dá em muitas frentes, deslegitima não apenas a sociabilidade dos grupos marginalizados (embora seja sobre esses que se faça sentir com mais violência), como o que Alfredo Bosi chama de "ethos agromercantil" ${ }^{17}$ do liberal de primeira hora, autoritário e rural - ethos que Anastácio encarna com a perfeição de um tipo literário. Um diálogo, iniciado pelo risível comendador Sancho, cujo conjunto de ações ridículas que protagoniza ao longo do romance serve para invalidar seu ponto de vista, nos dá uma boa dimensão de como esse problema é posto:

[Ele, Anastácio] Quer em cada casa um convento, e em cada moça uma freira: é o herdeiro das carunchosas ideias do século passado! [E Sancho continua, um pouco adiante] O Sr. é um cego [...] que não vê as luzes do século!

- Tenho assim meu receio delas, respondeu o roceiro, porque sinto que vão queimando, com muito cousa má, muita cousa boa.

- Queria que, como dantes, vivessem as pobres moças enterradas nos fundos das casas; que não aparecessem a pessoa alguma, que não viessem falar às visitas, que se casassem sem ter visto a cara dos noivos, e que apenas olhassem para a rua pelos buraquinhos das rótulas!... arrepia-se agora ao ver que num baile suntuoso uma bela jovem aceita o braço de um nobre cavalheiro, e vai com ele passear conversando agradavelmente ${ }^{\mathrm{I}}$.

O que existe entre Memórias da Rua do Ouvidor e Rosa, mais até do que qualquer acusação de incoerência que possa recair sobre Macedo, é o esfacelamento da economia moral desse paternalismo agrário.

Tratando do mesmo assunto, Gilberto Freyre argumenta, em Sobrados e mucambos, que as gelosias tinham uma função bastante clara nos sobrados urbanos: a proteção dos bens materiais guardados na casa, a mulher dentre ele. Assim, nos sobrados que preservavam com mais rigor a "pureza de costumes, as grades de madeira [as gelosias] eram completas, estendendo-se além da frente pelos dois extremos laterais e pela parte superior, onde atingiam a altura dos próprios sobrados, que assim tomavam feições de cadeias" busca repensar as gelosias sob outro ponto de vista, ressaltando antes seu caráter mediador do que o limitador entre os ambientes que separam, Marins não deixa de apontar como a experiência que se depreende a partir da análise de objeto é distinta segundo a classe social: "Decerto que os pudores e recatos eram apanágios

\footnotetext{
I6 MARINS, Paulo César Garcez. Através da rótula, 200I, op. cit., p. 28.

I7 BOSI, Alfredo. Dialética da colonização. São Paulo: Cia. das Letras, I992, p. 24I.

I8 MACEDO, Joaquim Manuel de. Rosa, op. cit., p. I4, I.

I9 Idem, Memórias da Rua do Ouvidor, op. cit., p. I36.
} 
das elites urbanas" ${ }^{20}$. Num certo sentido, embora afirme com todas as letras, Marins não se coloca inteiramente contra a interpretação de Gilberto Freyre, mas a matiza no que se refere ao "estereótipo da casa claustral" autor de Sobrados e mucambos faz crer, e a amplia, trazendo para o primeiro plano a experiência dos grupos marginalizados ${ }^{22}$, os quais fugiam ao radar aristocratizado de Gilberto Freyre.

Mas o fim das gelosias é apenas um dos aspectos das mudanças estruturais por que passa a sociedade brasileira ao longo do século XIX. Junte-se a isso novas possibilidades de comportamento para as mulheres - ainda bastante limitadas, ressalte-se - e se poderá ter uma ideia de como a lógica senhorial passa a perceber esse conjunto de mudanças como afronta à sua autoridade, agora incapaz de confiná-las com a mesma efetividade do passado. Não só as casas não mais gozavam da mesma arquitetura protetora, como as mulheres passaram a frequentar outros ambientes, onde a presença de estranhos não podia ser inteiramente controlada.

Como se não bastasse a maior exposição da mulher ao que se julgava como perigos de um mundo sem compasso, a casa ainda tinha que lidar com outro fator problemático para o repertório de manutenção da ordem: a escravidão doméstica. Necessários não apenas para o andamento das tarefas cotidianas nos sobrados, mas para o sistema imperial como um todo, os escravos faziam a ponte entre a desordem da rua e a ordem do lar. Na esteira aberta pela crítica de Marins, pode-se dizer que a dicotomia casa/rua não dá conta da experiência daqueles que não gozavam do privilégio das classes altas. Desprovida de nuances e de especificidade histórica, não dará conta sequer da experiência desses grupos abastados. Contudo, no mundo autoimaginado da ideologia senhorial, especialmente em contexto de consolidação de uma hegemonia conservadora, dentro do qual escreve Macedo, a fronteira entre os espaços ainda goza de uma dimensão simbólica de peso. Às mulheres de boa família, que são as protagonistas das obras que iremos analisar aqui, não era permitido sair de casa sem a devida companhia. Na verdade, segundo Maria Odila Dias, "quase não aparecem senhoras das classes dominantes" nas ruas ${ }^{23}$. Seu espaço, ao contrário das mulheres pobres, das libertas ou das escravas, ainda era a casa, onde sua pureza

20 MARINS, Paulo César Garcez. Através da rótula, I997, op. cit., p. 55. Maria Odila Dias também aponta para esse funcionamento, que varia a depender da classe social: "O processo de hegemonia da Corte do Rio de Janeiro era compatível com a penumbra discreta das rótulas”. DIAS, Maria Odila. Prefácio. In: MARINS, Através da rótula: sociedade e arquitetura no Brasil, séculos XVII a XX. São Paulo: Humanitas, 200I, p. 9-I9. p. I8.

2I MARINS, Paulo César Garcez. Através da rótula, I997, op. cit., p. 52.

22 Para outro resgate dessas experiências de mulheres para quem, ao contrário das classes altas, o trânsito no espaço público é uma necessidade de sobrevivência, ver: DIAS, Maria Odila. Quotidiano e poder em São Paulo no século XIX. São Paulo: Brasiliense, I984.

23 Ibidem, p. I4. 
podia ser preservada ${ }^{24}$. Nesse sentido, a escravidão doméstica não deixa de ser um paradoxo com o qual as estruturas de dominação senhorial têm que lidar: "para que a casa funcionasse, ela teria que se tornar cronicamente vulnerável aos perigos da rua”25.

Na cena analisada, percebemos a formalização literária de dois elementos capazes de provocar ansiedade na classe senhorial. A mulher aburguesada, preocupada com a moda, os namoricos e os bailes, e o escravo, que age sem o consentimento do senhor, constituem, ambos, dois tipos sociais sobre os quais recaem as preocupações de manutenção da ordem. $\mathrm{O}$ acesso que temos, através da análise desses tipos, diz menos do mundo real do que das visões de mundo e dos códigos sociais dentro dos quais ganham sentido, que são historicamente determinados. O escravo portador da carta amorosa, por exemplo, tem uma dimensão real. Era ele, efetivamente, quem levava e trazia a correspondência entre as casas. Contudo, quando o elemento externo é incorporado à obra literária, se sobrepõe à dimensão mimética outra, simbólica, na qual se inscreve uma experiência social ${ }^{26}$, que também pode ser vislumbrada em outros documentos. Tanto um, a mulher, quanto o outro, o escravo, são, segundo o direito civil da época, incapazes. Num livro de I868, O sistema representativo, em que participa do debate sobre o sistema político brasileiro, José de Alencar pontua como este é "a face coletiva da mesma comunhão, de que a sociedade civil é a face individual" 27 . Interessa aqui menos o desenvolvimento da sua argumentação ${ }^{28}$ do que o pressuposto do qual ele parte. A ordem e a harmonia do corpo político dependem da sua capacidade de espelhar a ordem e a harmonia da sociedade civil, assentada num escalonamento que não só liga verticalmente todos os membros do corpo social, como entrega "a direção moral da sociedade aos melhores homens, habilitados para o seu

24 "As mulheres de elite custaram a se aburguesar, por exemplo, no sentido de se vestirem para fazer compras nas ruas. Durante muito tempo continuaram a fazer suas encomendas por meio dos comissários ou eventualmente dos catálogos dos grandes magazines. Não importava tanto serem vistas, seria até preferível manter-se discretamente invisíveis para melhor articular as lideranças familiares, que em nada distinguiam das lideranças propriamente políticas”. DIAS, Maria Odila. Prefácio, op. cit., p. I8). Engraçado notar como, nessa passagem, Dias e Anastácio parecem concordar - a casa é mesmo o espaço da mulher de classe alta —, ainda que o façam de maneira inteiramente distinta. Para Dias, em linha com a sensibilidade mais moderna, é onde ela exerce sua agência. Para Anastácio, como bom tipo senhorial que é, a adequação às boas normas domésticas é a primeira tarefa de uma mulher.

25 GRAHAM, Sandra Lauderdale, I988, op. cit., p. 27 (tradução nossa).

26 Para uma discussão mais detalhada a respeito dessa posição metodológica, ver: CANDIDO, Antonio. Crítica e sociologia. In: . Literatura e sociedade. 9. ed. Rio de Janeiro: Ouro sobre Azul, 2006, p. I3-25; e DARNTON, Robert. O grande massacre de gatos e outros episódios da história cultural francesa. 2. ed. Rio de Janeiro: Graal, I986.

27 ALENCAR, José de. O systema representativo. Rio de Janeiro: B. L. Garnier, I868, p. 8I.

28 Para uma análise do tipo, cf. RIZZO, Ricardo Martins. Entre deliberação e hierarquia: uma leitura da teoria política de José de Alencar (I829-I877). Dissertação (Mestrado em Ciência Política). Faculdade de Filosofia, Letras e Ciências Humanas, Universidade de São Paulo, 2007. 
exercício"29, exatamente porque os demais -“[a] mulher, o menor, o alienado"30 - não podem fazer uso próprio dos próprios direitos ${ }^{3 \mathrm{I}}$.

Como veremos, essa relação que estrutura a sociedade em dois grupos - um passível de problematizar a ordem social quando não submetido ao outro, responsável pela sua direção moral - encontra formulação literária no tropo do escravo que leva uma carta amorosa à personagem feminina; uma formulação que adquire significados distintos segundo a disposição desses elementos dentro da estrutura das obras.

\section{TRÊS TEMPOS DE UM MESMO TROPO - I. RETORNANDO A MACEDO}

Na paráfrase que fiz do capítulo XI, não mencionei por uma simples razão o momento em que o pajem da moça lhe entrega a carta de Juca: ele praticamente não tem importância para o desdobramento da ação. Para o andamento da narrativa, vale menos que Rafael tenha levado uma carta a Rosa do que a demonstração da inconsequência dela, que não respeita as boas regras de conduta. Porém, por mais rápida que tenha sido a menção, cabe explorá-la com algum detalhe: "Quando Rosa acabava de descer o último degrau, apareceu-lhe como por acaso, o mais esperto dos pajens de seu pai; e parando perto dela, estendeu o braço procurando entregar-lhe um papel, que estava dobrado à maneira de carta; mas que não trazia sobrescrito"32. A princípio, Rosa quer saber se fora o pai quem mandara entregar o recado e se ele sabia do que se tratava, o que o pajem nega, dando certo ar de inocência à ação da moça.

Tanto a esperteza de Rafael quanto a desatenção de Rosa são fundamentais para a manutenção de certos limites à desordem da protagonista, fora dos quais seu retorno ao universo da ordem fica comprometido. Isso quer dizer que, para que Rosa alcance o casamento com o seu escolhido no final do enredo, é preciso que ela não se iguale, em suas loucuras de juventude, a outras moças, cujos comportamentos seriam, esses sim, irredimíveis. Toda a estrutura do capítulo depende desse passo. Posteriormente, quando a conversa com o tio envereda pela comparação da moralidade pública do baile em oposição à hipocrisia da troca secreta de correspondência, ela faz questão de ressaltar que não é afeita a esse tipo de comportamento: “Eu digo, meu tio que nunca na

29 Ibidem, p. 40 .

30 ALENCAR, José de. O systema representativo, I868, op. cit, p. 8I.

3I O escravo entra tangencialmente na classe dos incapazes. Ao contrário dos demais, ele não possui direitos de soberania, mas ainda assim, "está sujeit[o] como a família a seu chefe". Ibidem, p. 80. Isso tem origem na defesa que Alencar faz da escravidão. A tolerância e generosidade da classe senhorial transformou para melhor, sem qualquer ingerência do Estado, um sistema que reconhece como injusto: "Pode-se afirmar que não temos já a verdadeira escravidão, porém um simples usufruto da liberdade, ou talvez uma locação de serviços contratados implicitamente entre o senhor e o estado como tutor do incapaz". ALENCAR, José de. Ao Imperador - Novas cartas políticas de Erasmo. Rio de Janeiro: Typ. de Pinheiro, I867, p. 29.

32 MACEDO, Joaquim Manuel de. Rosa, op. cit., p. I4I, I. 
minha vida escrevi cartas desta natureza"33. Por fim, vencido o desafio, tranquiliza a boa sociedade ao afirmar: "não quero escrever a homem algum"34. (A título de exemplo, lembremos de D. Gabriela, de A moreninha, que se correspondia com cinco pretendentes ao mesmo tempo. Sua única função no romance é servir como demonstração de um comportamento inapropriado, que será ironizado pelo protagonista no final do enredo ${ }^{35}$.) Ou seja, não há, entre Rosa e seu escravo, cumplicidade alguma.

Assim, a esperteza do pajem é crucial para a manutenção dos limites dos desvarios da moça, e é esse atributo que precisa ser pensado com um pouco mais de cuidado. No caso, a esperteza até pode ser uma qualidade necessária para aqueles que têm que lidar com o espaço perigoso das ruas. Não é de estranhar que, segundo Graham, tenha havido uma preferência por serviçais mais velhos, que seriam mais tarimbados para lidar com as armadilhas daquele espaço social. O problema para o repertório senhorial diz respeito à possibilidade de contágio, que seria o uso dessa astúcia no ambiente doméstico: "Eles [os senhores] assumiam ainda que os serviçais, uma vez fora do domínio direto da autoridade paterna, muito provavelmente se entregariam a maus hábitos" 36 e, pior, poderiam trazê-los para dentro de casa.

Macedo já havia tratado do tema, de maneira mais demorada, em seu primeiro romance. Logo no capítulo II de A moreninha nos deparamos com uma carta de Fabrício para Augusto, na qual lemos os dissabores do namorico daquele com D. Joaninha. A história toda começa com a intervenção de Tobias, pajem da moça. O mais importante para o meu argumento, contudo, diz respeito à agência do escravo: "Não me foi preciso chamá-lo: bastou um movimento de olhos para que o Tobias viesse a mim rindo-se desavergonhadamente" ${ }^{37}$. A partir daí Tobias assume as rédeas da situação e revela a Fabrício tudo o que ele precisa saber sobre a moça - seu endereço, nome da mãe, profissão do pai, já falecido, inclusive que ela está morrendo por casar. Quando solicitado que leve um recado a D. Joaninha, Tobias não vacila:

[...] com licença de meu senhor, eu cá sou doutor nisto; meus parceiros me chamam orelha de cesto, pé de coelho e boca de taramela. Vá dizendo o que quiser, que em menos de dez minutos minha senhora sabe tudo; o recado de meu senhor é uma carambola que, batendo no meu ouvido, vai logo bater no da senhora D. Joaninha $3^{38}$.

33 Ibidem, p. I48, I.

34 Ibidem, p. I5I, I.

35 MACEDO, Joaquim Manuel de. A moreninha. 9. ed. Rio de Janeiro: Garnier, s.d. [1844], p. I28.

36 GRAHAM, Sandra Lauderdale. House and street, op. cit., p. 46 (tradução nossa).

37 MACEDO, Joaquim Manuel de. A moreninha, op. cit., p. 2I.

38 Ibidem, p. 22. 
Lendo a contrapelo39, poderíamos fazer uso da perspectiva aberta por Sidney Chalhoub $^{40}$ e afirmar que temos aqui - como será o caso de Pedro, em $O$ demônio familiar, de Alencar, assim como é bem possível que tenha sido o do pajem de Rosa - um escravo que se vale das oportunidades tais quais se lhe apresentam de modo a ganhar uns cobres enquanto dure a relação a que ele serve de intermediário ${ }^{4 \mathrm{I}}$. Sob a perspectiva senhorial, contudo, que é a que organiza o sentido das ações nos romances, o que se apresenta é a desordem doméstica trazida pelo trânsito não supervisionado do escravo entre a casa e a rua. Noutras palavras, quando as ações são deixadas a cargo dos incapazes, é a moral da esfera doméstica - e, portanto, a segurança do corpo social como um todo - que sai perdendo.

Voltando a Rosa, note-se ainda que o capítulo tem lá seus problemas. A moça, apesar de ter recebido a carta inocentemente, como bem sabemos, não é nenhuma santa. Vaidosa, está mais preocupada com a vida mundana dos bailes do que com aquisição da educação moral necessária para se tornar uma boa mãe de família, que, segundo Anastácio, é "objeto de importância imensíssima para a sociedade"42. E ele continua, apontando sem meias palavras o problema com qual estamos lidando:

[...] é necessário também dizer que, se a missão da mãe de família é árdua em toda a parte do mundo, no Brasil é particularmente muito mais espinhosa, porque no Brasil cada homem guarda dentro de sua própria casa um inimigo do coração de seus filhos, um poderoso elemento de desmoralização; em uma palavra, porque no Brasil existe a escravatura ${ }^{43}$.

Só que, no romance, o problema não está na escravatura, mas na própria moça, que, além de ser desajuizada, tem um pai que não lhe dá limites. (Lembremos que, em sua casa, os horários das refeições ficam a cargo dos caprichos dela.) É o seu comportamento extravagante e o de Juca que porão efetivamente em risco a paz

39 O episódio das cartas de D. Gabriela também pode ser lido a contrapelo. Conversando com as amigas, em segredo, ela confessa que se corresponde com cinco dos vinte pretendentes, "isto é só para ver qual dos cinco quer casar primeiro". MACEDO, Joaquim Manuel de. A moreninha, op. cit., p. I28. Todo o capítulo está construído para desmerecer essas moças, entregues a um tempo sem qualquer moral. Porém, se lembrarmos que o espaço de oportunidade de vida dessa mulher é bastante estreito, seu sucesso sendo medido principalmente pelo casamento que contrai, o fato de ela se corresponder com cinco é uma maneira de se tentar tomar as rédeas da situação. Na verdade, A moreninha é recheado de passagens desse tipo, pedindo uma leitura feminista.

40 CHALHOUB, Sidney. Machado de Assis, historiador, op. cit.

$4 \mathrm{I}$ "[Tobias] Entende que todos os dias lhe devo dar dinheiro, e persegue-me de maneira tal que, para ver-me livre dele, escorrego-lhe - cum quibus - a despeito da minha má vontade”. MACEDO, Joaquim Manuel de. A moreninha, op. cit., p. 25-26. O mesmo acontece com Pedro, o escravo de O demônio familiar: "Ele [Azevedo] me deu dez mil réis [...] [p]ara entregar o bilhete a nhanhã”. ALENCAR, José de. O demônio familiar. Rio de Janeiro: Typ. Soares \& Irmão, I858, p. I9.

42 MACEDO, Joaquim Manuel de. Rosa, op. cit., p. I3, I.

43 Ibidem. 
do lar. Daí que, ao final, seja ela e não o escravo a sofrer a punição necessária para o restabelecimento da ordem. Será preciso outra configuração do tropo para que a questão da escravidão doméstica possa ser trazida à luz.

\section{TRÊS TEMPOS DE UM MESMO TROPO - II. O EXORCISMO DE AlENCAR}

Esse mesmo tropo é retomado por José de Alencar em O demônio familiar, que subiu aos palcos em dezembro de 1857. Agora, porém, o tropo tem uma dimensão muito maior, sendo tratado diretamente em nove cenas diferentes e com implicação inclusive no seu desfecho. Nada a estranhar, afinal, as diabruras do escravo da casa são o mote da peça. Apesar da semelhança estrutural, que é o que caracteriza o tropo, veremos que Alencar corrige (sob o ponto de vista senhorial) uma distorção macediana, tornando menos violento o processo de manutenção da paz familiar.

As cenas nas quais me deterei dizem respeito a uma das muitas confusões causadas pelo comportamento inconsequente de Pedro, que é o escravo doméstico da família de Eduardo. Nesse sentido, pode-se dizer que, em linhas gerais, Alencar parte da mesma percepção da questão que Macedo tinha: a escravidão é um mal que habita a casa da boa sociedade brasileira. Só que a família do romance de Macedo tinha na irresponsabilidade dos herdeiros outros e piores problemas com que lidar. Em Alencar, isso está corrigido. Carlotinha, irmã de Eduardo, ao contrário de Rosa, é uma boa moça. Daí que a tarefa de Pedro - que, a exemplo de Tobias e, quem sabe?, de Rafael, tomou dinheiro do pretendente, Alfredo, para entregar uma carta a ela seja um tanto mais penosa. Como, ao contrário de Rosa, o respeito à moral e o bom senso da moça a impedem de receber a carta que trouxe, ele tem que deitá-la às escondidas no bolso da sua roupa. Depois, de modo a fazê-la dar uma resposta, trata de convencê-la de que Alfredo, a despeito da imprudência, é um bom partido. Todas as características usadas por Pedro como critério de valor para elevar Alfredo aos olhos da moça - a roupa, o porte, os charutos que fuma, a maneira como mexe o bigode etc. - são típicas dos antagonistas desfrutáveis de Macedo e do próprio Alencar 44.

Para Décio de Almeida Prado, O demônio familiar gira em torno do confronto entre duas forças: uma - a do "homem", do "senhor", do "doutor" Eduardo, diz respeito ao polo da ordem (termo que Prado não usa); a outra, a de Pedro, se caracteriza pelos signos de sua incapacidade, que deve ser entendida no sentido legal, já mencionado. Ele é "o menino", "o escravo", “o analfabeto". Assim, enquanto Eduardo se encarrega de defender as normas de uma sociedade senhorial com certos traços aburguesados, “Pedro será, em larga medida, o elemento contrário, não só de

$44 \mathrm{O}$ fato de Pedro dominar esse repertório o torna ainda mais perigoso para os padrões tradicionais. Para ter a dimensão simbólica da moda como afronta à sociedade tradicional, ver: GAMA, Miguel do Sacramento Lopes. O carapuceiro: crônicas de costumes. São Paulo: Cia. das Letras, I996.

45 PRADO, Décio de Almeida. Os demônios familiares de Alencar. Revista do Instituto de Estudos Brasileiros, São Paulo, n. I5, I974, p. 5I. Disponível em: 〈http://dx.doi.org/Io.II606/issn.23I6-90IX.voiI5p27-57〉. Acesso em: 3 mar. 20I3. 
fantasia, de espontaneidade, mas também de realismo, de descrição dos costumes"46. Num movimento típico do grupo intelectual e do período a que pertence, Prado pontua a ligação quase intrínseca da peça com sua fonte europeia, de modo a destacar que, ao final, seu ponto alto está na introdução e tratamento do elemento nacional nesse esquema; em Pedro, em suma. Contudo, ao chamar em causa o escravo como cronista da cena carioca de meados do século XIX, informando sobre as vestimentas dos rapazes, as noites de baile, as casas de moda, os rituais de namoro, Prado não leva em consideração como isso tudo ocupa uma posição rebaixada no universo de valores da peça. Assim, as crônicas da vida mundana carioca de que se vale Pedro dão conta, de maneira muito mais detalhada do que a de Macedo, da retórica do contágio. O conhecimento da gramática das ruas pelo escravo que nelas transita é perigoso quando trazido para dentro de casa, onde habita a moça.

Machado de Assis está correto na avaliação que faz do cuidado que Alencar teve em não transformar Pedro num personagem "odioso e repugnante" 7 . Contudo, ainda que exista efetivamente uma indulgência na recepção de um escravo cuja função no enredo é a de ser o "intrigante doméstico", Pedro cumpre o seu papel de "demônio", tentando a moça de família para o mau caminho. Pressionado por Alfredo, o pajem cobra uma resposta de Carlotinha, que, novamente, marca sua diferença em relação a Rosa: “Escrever, nunca; não tenho ânimo!..."18. Pedro sugere, então, outra forma de comunicação: que ela pegue duas flores, mande uma para o pretendente e prenda a outra no cabelo, sinalizando interesse. O diálogo chama em causa, mais uma vez, a capacidade de desorganização doméstica produzida pelo escravo. Carlotinha, menos santa do que parece, havia pensado nesse estratagema, pois já traz consigo as flores e se mostra indecisa. Reconhece a norma, mas, fraca e incapaz, está tentada a violá-la.

CARLOTINHA, põe a mão no seio. - Estão aqui [as flores].

PEDRO. - Melhor! (Estendendo a mão) Dê cá, nhanhã.

CARLOTINHA, dando. - Mas olha!... Não!

PEDRO, tomando. - Hi!... Sr. Alfredo vai comer esta violeta de beijo só, quando souber que esteve no seio de nhanhã!

CARLOTINHA. - Dá-me ! não quero!... (Pedro sai correndo.)49.

Note como as indicações cênicas não deixam margem para dúvida sobre o papel do escravo nesse processo que poderia muito bem levar à perdição da moça. A tendência para o equívoco faz parte da imaturidade, o que não é necessariamente algo ruim. $\mathrm{O}$

46 Ibidem, p. 52.

47 ASSIS, Machado de. Semana literária I. Diário do Rio de Janeiro, 6 mar., I866, p. I.

48 ALENCAR, José de. O demônio familiar, op. cit., p. 6I.

49 Ibidem, p. 62. 
problema é que, associada à má influência do escravo e sem a devida supervisão, essa combinação é, segundo o repertório de dominação senhorial, desastrosa.

Décio de Almeida Prado se opõe veementemente à posição de Raimundo Magalhães Jr., para quem o desfecho de $O$ demônio familiar é reacionário. Para Prado, a peça é "sem dúvida abolicionista"5o. Dentre os argumentos que elenca para defender essa tese, bastante contraintuitiva se lembrarmos das cartas que Alencar escreveu ao imperador em I866, um me interessa mais de perto: "A liberdade é [...] condição indispensável ao amadurecimento do homem" 5 . Ao alforriá-lo no final, como punição por sua conduta inconsequente, Eduardo retira Pedro da classe dos incapazes, tornando-o imputável. O maior problema do argumento não é sequer ele não reconhecer a acepção negativa que a liberdade pode assumir num sistema senhorial ou ainda que a metáfora da incapacidade é parte do arsenal de dominação conservadora, que estabelece que a direção moral da sociedade pertence a um grupo social bastante reduzido; o problema é, antes, que ele, o argumento, não lida com o fracasso inicial de Eduardo no seu papel de senhor e chefe de família. Como Alencar escreve em suas cartas da década de I860, a escravidão faria parte do processo de civilização dos povos bárbaros, que muito têm a aprender com a boa sociedade. Daí que Eduardo tenha que assumir sua falha como chefe de família digno de nome. Durante muitos anos, ele se valeu dos serviços de Pedro para "gozar desses amores fáceis que duram alguns dias" 52 . E conclui, dirigindo-se a Carlotinha depois que ela lhe confessa o imbróglio com Alfredo: "Imprudente, eu abrigava no seio de minha família, no meu lar doméstico, a testemunha e o mensageiro de minhas loucuras: alimentava o verme que podia crestar a flor de tua alma. Sim, minha irmã! Tu cometeste uma falta; eu cometi um crime!"53. Em suma, um senhor que age de maneira inconsequente não deixa de ser responsável pelos atos daqueles que vivem sob o seu jugo.

Dentro do sistema social do império brasileiro, o chefe de família não apenas encabeça o grupo pelo qual é responsável - mulheres, crianças, escravos, agregados etc. -, como, na arena social, o representa, no sentido político, como o único cidadão pleno ${ }^{54}$. Ele, portanto, para que se mostre digno da posição que ocupa, precisa controlar tudo o que se passa na sua casa. Eduardo está no fim do processo de transição entre o jovem irresponsável que dava vazão às suas "extravagâncias" e "loucuras" - o protagonista macediano por excelência - e o seu novo papel social e literário de defensor da ordem doméstica. Pedro age, ao longo da peça, nesse interregno, no intervalo de formação da sua consciência de senhor proprietário ciente de todas as suas prerrogativas. O pajem é, em larga medida, reflexo do estágio inconsequente do comportamento de Eduardo. Numa excelente colocação machadiana, à qual volto na seção seguinte, o escravo perfeito não é aquele que é apenas submisso, mas, sim,

50 PRADO, Décio de Almeida. Os demônios familiares de Alencar, op. cit., p. 48.

5 I Ibidem, p. 49.

52 ALENCAR, José de. O demônio familiar, op. cit., p. 66.

53 Ibidem.

54 ALONSO, Angela. Ideias em movimento, op. cit., p. 62. 
o que age como "espírito externo de seu senhor"55. Nesse sentido, alforriar ${ }^{56}$ Pedro é pôr fim a um estágio da sua vida e assumir as responsabilidades do outro.

Para concluir esta seção, resta ainda discutir como o desfecho desse subenredo também marca uma diferença importante e reveladora sobre o funcionamento do tropo entre Macedo e Alencar. Quando Rosa avisa ao tio, sem a menor sombra de arrependimento, que havia acabado de enviar uma carta sem que ele se desse conta, Macedo está encenando o pouco caso que os jovens fazem da autoridade e da moral. Carlotinha, ao contrário, logo após a cena em que Pedro foge com as flores, se apercebe do seu comportamento pouco cristão e vai se confessar ao irmão, que toma as devidas providências para preservar a ordem doméstica. Note-se ainda como essa adequação do comportamento refletirá no desfecho da história. O descaso de Rosa para com a autoridade tradicional leva a uma situação de crise, que põe em risco a sua honra e a da sua família. Daí que a correção de rumo da moça seja bastante violenta, parte do processo de submissão à vontade tanto do tio quanto do pai de Juca, Mariano, numa reposição quase que completa do repertório de dominação senhorial do qual ela fizera graça. Alencar, que era desconfiado desses arroubos românticos e buscava, no palco, apresentar paixões menos arrebatadoras, corrige os rumos do enredo ao eliminar a extravagância feminina. Carlotinha, mais comportada, tem do irmão o beneplácito de receber em casa as visitas de Alfredo, cuja corte ele agora passa a supervisionar. Nesse sentido, a única agência em cena é a do escravo que leva a carta e, por isso, somente ele é responsabilizado ao final do enredo. É verdade que as diferenças entre Eduardo e Anastácio na condução do desfecho de suas respectivas histórias põem em cena funcionamentos distintos da autoridade. Esta, contudo, continua a mesma: senhorial, masculina e branca - como sempre, é o senhor-proprietário, chefe de família, quem responde pela ordem da casa.

\section{TRÊS TEMPOS DE UM MESMO TROPO - III. ABERTURA PARA UMA NOVA ORDEM?}

Comecemos, como tem sido de praxe, pela caracterização do portador da carta. Raimundo não só é muito mais velho do que Rafael e Pedro, ele sequer é mais escravo. Luiz Garcia fez questão de alforriá-lo assim que o recebeu de herança do pai. Contudo, "[v]endo-se livre, pareceu-lhe [a Raimundo] que era um modo de o expelir de casa, e sentiu um impulso atrevido e generoso. Fez um gesto para dilacerar a carta de alforria, mas arrependeu-se a tempo. Luiz Garcia viu a generosidade, não o

55 ASSIS, Machado de. Yaya Garcia. Rio de Janeiro: Typ. do Cruzeiro, I878, p. 9.

$56 \mathrm{O}$ ato da alforria não é necessariamente um gesto abolicionista. Ao longo dos debates a respeito da Lei do Ventre Livre, em I87I, o projeto alternativo, apresentado por Perdigão Malheiro em I8 de agosto desse ano, contrapunha-se ao avanço do Estado sobre as prerrogativas dos senhores. Segundo Needell, Malheiro propunha que a abolição se desse noutros termos, "colocando o processo de manumissão nas propriedades nas mãos dos próprios proprietários”, o que seria uma forma de manter inalterada “a sua posição hegemônica na economia moral da tradição rural”. NEEDELL, Jeffrey. The party of order: the conservatives, the state, and slavery in Brazilian monarchy, I83I-I87I. Stanford: Stanford UP, 2006, p. 299; p. 289. 
atrevimento"57. A sutileza de Machado deixa em aberto a existência ou não de cálculo por parte de Raimundo, cuja ação é construída em sintonia com a ideologia senhorial, que sai tranquilizada pela demonstração do desejo do escravo, ainda que não levado às últimas consequências, de permanecer ligado ao seu senhor. Em certa medida, Machado traz para o início do seu romance o gesto com que Eduardo fecha O demônio familiar, fazendo Raimundo agir com a preocupação que a ideologia dominante julga necessária àquele que não mais goza da proteção da família.

Segundo Sidney Chalhoub - num estudo que busca trazer ao primeiro plano estratégias como essas, necessariamente ambíguas, que eram utilizadas pelos dependentes de modo a garantir espaços de autonomia dentro de um sistema extremamente hierarquizado e violento -, um dos pontos centrais do ideário de dominação senhorial é a ausência de qualquer possibilidade de uma perspectiva externa à do senhor-proprietário ${ }^{58}$. Nesse mundo idealizado pelos mandantes, Raimundo é o escravo perfeito, ainda que não seja mais, legalmente, escravo, pois "submisso e dedicado", "parecia feito expressamente para servir a Luiz Garcia"59. É ainda esse ponto de vista que domina a dupla possibilidade de interpretação do gesto do ex-escravo. A generosidade, a primeira, existe em função tanto da expressão da gratidão ao seu senhor quanto da demonstração da importância de que esta seja manifesta através do vínculo institucional; o atrevimento, a segunda possibilidade de interpretação, se revela em face da afronta à vontade de Luiz Garcia, que era de libertá-lo.

Ainda que a ambiguidade do gesto exista, Raimundo é caracterizado na linha do escravo ideal, aquele que se mantém ligado ao senhor mesmo depois de alforriado, pois reconhece, ao contrário de Pedro, o quanto é necessário manter o vínculo de dependência, mesmo que a liberdade lhe seja oferecida. Contudo, há outras passagens do romance, algumas ainda na caracterização inicial, que venho comentando, as quais limitam o alcance daquela ambiguidade: "Raimundo foi dali em diante [do momento da alforria] um como espírito externo de seu senhor; pensava por este e refletia-lhe o interior, em todas as suas ações, não menos silenciosas que pontuais" ${ }^{\circ}$. A frase do narrador, em terceira pessoa, sem qualquer indicação que se refira a um discurso indireto que passe por Luiz Garcia, parece estar fundada nos códigos culturais bastante precisos e senhorialmente determinados, que veem o escravo como projeção do senhor. Na linha aberta por Chalhoub, parece claro que Machado, escrevendo depois de I87I, quando a hegemonia conservadora já não funciona com a mesma efetividade, demonstra toda uma maneira outra de ler o mundo que escapa à visão limitada dos senhores. De qualquer sorte, é preciso demarcar a grande diferença que existe entre, de um lado, Rafael e Pedro e, de outro, Raimundo, que, ao contrário dos outros dois, não parece oferecer qualquer espécie de risco à ordem doméstica.

Em termos do enredo central, a morte de Luiz Garcia complica o encaminhamento

57 ASSIS, Machado de. Yaya Garcia, op. cit., p. 9.

58 CHALHOUB, Sidney. Machado de Assis, historiador, op. cit.

59 ASSIS, Machado de. Yaya Garcia, op. cit., p. 9.

60 Ibidem. 
da disputa amorosa. No início do romance, a narrativa girava em torno do amor ao mesmo tempo sincero e violentamente senhorial de Jorge por Estela, agregada da sua casa, ao qual se opunha Valéria, mãe do moço, que, com a ajuda a contragosto e pouco enfática de Luiz Garcia, acaba por convencer o filho a se alistar e ir combater no Paraguai. Por fim, para jogar a pá de cal sobre qualquer esperança que Jorge pudesse vir a ter apesar da distância, trata de incentivar o casamento de Estela e Luiz Garcia. Os anos passam, a guerra se estende, Valéria morre e, por fim, Jorge, agora tenente-coronel do exército, volta condecorado ao Rio de Janeiro. Num determinado momento do enredo, lá para o meio do livro, por causa de uma carta que Jorge havia escrito a Luiz Garcia ainda nos anos da guerra, Iaiá percebe, pelas reações de Estela, que, embora não possa ter certeza, houve algo entre sua madrasta e o amigo da família. De modo a preservar o casamento do pai, a moça, calculadamente - uma palavra, lembremos, sempre problemática quando a história gira ao redor de questões amorosas -, age no sentido de conquistar Jorge, mesmo que afirme não o suportar. Quando Luiz Garcia morre, a situação, que estava encaminhada com o compromisso entre Jorge e Iaiá, se complica. A moça, movida por capricho e ciúme pelo que sabia, achando que agora nada mais impediria a união de Estela e Jorge, não só rompe o compromisso - através de uma carta escrita em segredo -, como escreve outra, aceitando o pedido que lhe fora insinuado por Procópio Dias, um negociante mais velho e um tanto escuso, por quem não nutre nenhuma espécie de afeto. É nesse ponto do enredo em que nos encontramos, já no final do livro (na edição de que me valho, página 300 de um total de 324), que Machado de Assis, a exemplo de Joaquim Manuel de Macedo e de José de Alencar, também se utiliza, em Iaiá Garcia, romance de I878, do mesmo tropo do escravo portador de uma carta amorosa, mas o coloca inteiramente de ponta à cabeça - a começar pelo fato de que o portador não é mais escravo, alteração cujas implicações discuto com mais detalhes adiante, nas considerações finais.

Quem escreve a carta não é mais um pretendente masculino, que se vale do escravo de modo a burlar o controle senhorial de acesso à mulher. Desfeito o casamento com Jorge, um excelente partido, especialmente se considerarmos sua posição social de agregada, Iaiá Garcia reflete sobre seu futuro: "foi então que lhe lembrou Procópio Dias. Não encarou a ideia sem repugnância; aceitável na palestra, Procópio Dias era-lhe antipático para a convivência conjugal. [...] Que muito? Era um marido; não exigia outro mérito" ${ }^{\text {". }}$. Em chave distinta da comentada quando tratamos brevemente dos muitos correspondentes de D. Gabriela em A moreninha, a passagem também diz muito sobre as perspectivas abertas para a mulher já no último quarto do século XIX. Revela o espírito prático de Iaiá, que, em situação de crise, se move segundo uma matemática de prós e contras, sendo a ausência de amparo em contexto senhorial o pior dos cenários ${ }^{62}$. Um ponto do tropo, contudo, se mantém. A carta é usada como um meio para fugir ao escrutínio da autoridade.

A terceira inversão machadiana diz respeito ao vetor. As cartas de Juca e de

6I Ibidem, p. 298.

62 Para outra perspectiva sobre a mulher e o casamento no Brasil oitocentista, em que se põe em discussão o papel desprestigiado das solteiras, ver: GRAHAM, Sandra Lauderdale. Caetana diz não: história de mulheres da sociedade escravista brasileira. São Paulo: Cia. das Letras, 2005. 
Alfredo vêm de fora, da rua, para dentro de casa. Seu efeito literário depende do medo que se tem da ruptura dessa divisão geográfica, cujas implicações simbólicas já foram discutidas. É verdade que, no caso de Rosa, há uma resposta para a carta de Juca, a qual tem uma dupla finalidade. Uma, de enfatizar a questão principal do enredo, centrado nas inconsequências dessa juventude educada segundo o que pregava a moral pouco cristã do tempo. Junto a essa, devido à posição ambígua da protagonista, há ainda uma dimensão moralizante, que busca interromper a correspondência e coibir, bem ao estilo senhorial, ressalte-se, outras ações inapropriadas por parte do escravo: "Se uma outra vez ousares encarregar-te de comissão igual àquela, de que te encarregaste hoje, fica sabendo, que eu direi a meu pai para te fazer castigar, como mereces" ${ }^{\prime 3}$. A carta de Iaiá não tem pretensão de impor qualquer espécie de limite, pelo contrário. Busca dar início ao compromisso que levaria ao casamento, o que, como se sabe, é coisa séria demais para ser tratada sem o consentimento da autoridade doméstica. Nesse sentido, como bem notou Estela, que se tornou, como sua madrasta, responsável pela moça depois da morte de Luiz Garcia, a "carta da enteada era um ato de insubordinação" 4 .

\section{Ainda Machado a título de CONSIDERaÇões finais}

A preservação da ordem é um dos valores mais importantes para a elite imperial brasileira oitocentista. Essa tarefa é responsabilidade de um grupo restrito, homens, brancos e proprietários que se viam como os únicos condutores morais de uma sociedade de incapazes, cuja agência, se deixada sem supervisão, é mais das vezes desastrosa. Nesse contexto, não é de estranhar que o enredo de casamento tenha sido a forma dominante da produção literária brasileira. Segundo Joseph Allen Boone, como "o rito de casamento em praticamente todas as culturas desempenha o papel de sustentar a ordem social estruturada" ${ }^{5}$, as narrativas amorosas passam a ter uma função ideológica considerável, pois repõem, no plano da forma, essa mesma preocupação. Daí a importância de figuras como Anastácio e Eduardo, cuja função narrativa é trazer o enredo, que fora desestabilizado pelo escravo e pela mulher, para um desfecho seguro, em que a ordem doméstica seja preservada.

Contudo, se voltarmos à crise provocada pelas cartas de Iaiá, veremos que a galeria de personagens que deveria se ocupar desse papel já não é mais a mesma. Luiz Garcia, que respondia pela estabilidade do lar, como sabemos, acabara de morrer. Quem assume a chefia da casa é Antunes, pai de Estela, agregado dos mais serviçais, em quem o próprio Luiz Garcia sequer confiava. Jorge, que era quem o morto esperava que assumisse seu lugar, não só não tem disposição de espírito para tanto, como, no momento de crise, recorre "à intervenção de Estela" ${ }^{66}$. Noutras palavras, considerado

63 MACEDO, Joaquim Manuel de. Rosa, op. cit., p. I49, I.

64 ASSIS, Machado de. Yaya Garcia, op. cit., p. 299.

65 BOONE, Josehp Allen. Tradition counter tradition: love and the form of fiction. Chicago: The University of

Chicago Press, I987, p. 36 (tradução nossa).

66 ASSIS, Machado de. Yaya Garcia, op. cit., p. 300. 
sob o ponto de vista do repertório senhorial, há um espaço de autoridade não preenchido, tornando a insubordinação da moça ainda mais problemática.

Voltemos à cena da carta de Iaiá para vermos como Machado resolve o problema da preservação da ordem em contexto que Chalhoub chama de crise da hegemonia saquarema ${ }^{6}$. Pois bem, assim que termina de escrevê-la, Iaiá chama Raimundo para que ele a leve a Procópio Dias. Raimundo se mostra desconfortável com a ideia, hesita, afirma não gostar do homem, mas uma frase mais dura da moça - "Não lhe fales; basta deixar a carta em casa dele" 68 - sela a história, e o ex-escravo sai rumo a seu destino. Na verdade, o mais correto seria ter escrito que Raimundo parece cumprir a ordem da moça, uma vez que a carta não será entregue: "Raimundo não achou bonito que Iaiá escrevesse àquele homem, que não é seu pai nem seu noivo, e voltou para falar a nhanhã Estela"69.

Entre aquele momento da narrativa, em que Raimundo hesita, e o final, quando se descobre que Procópio nunca recebera a carta de Iaiá, Machado dedica umas poucas linhas às reflexões do ex-escravo: "Depois olhou para a carta, como se quisesse adivinhar o que ia dentro. Não era só pressentimento, mas também dedução do que ele via naquelas últimas semanas" 70 . Pressentimento e dedução não são duas palavras inocentes, longe disso. Dentro do universo cultural e literário de Macedo e Alencar, o negro criado dentro do sistema escravocrata seria incapaz de tal reflexão elaborada sobre o mundo à sua volta, agindo sempre como uma criança, sem medir as consequências de seus atos. Alencar, em sessão da câmara quando dos debates a respeito da Lei do Ventre Livre, afirma que "a liberdade concedida a essas massas brutas é um dom funesto". E arremata, pouco adiante: “Não basta [...] dizer à criatura, tolhida na inteligência e abatida na sua consciência: Tu és livre; vai; percorre o campo como uma besta-fera!..." ${ }^{71}$. Esse é um dos tropos fundamentais da retórica escravista. A liberdade do negro põe em risco a ordem social, porque, criados no cativeiro, os escravos não foram capazes de desenvolver as ferramentas necessárias para atuarem como cidadãos plenos. Machado, como bem demonstrou Chalhoub, conhecia como poucos os meandros desse debate e o retoma com engenhosidade em sua obra ficcional. Como visto, logo no começo do romance, o narrador apresenta Raimundo elencando, de maneira bastante clara, as características - "submisso e dedicado", "feito expressamente para servir", "espírito externo de seu senhor"72 - que o colocam em perfeita sintonia com o ideário senhorial. Contudo, é esse mesmo ex-escravo, sobre quem recai o peso de uma ideologia que o relega a uma posição subalterna, que se mostra, a par do pressentimento, capaz de um processo tão racional quanto o da dedução. $\mathrm{O}$ silêncio a respeito do casamento da moça com

67 CHALHOUB, Sidney. Machado de Assis, historiador, op. cit.

68 ASSIS, Machado de. Yaya Garcia, op. cit., p. 299.

69 Ibidem, p. 3 I5.

70 Ibidem, p. 299.

7I ALENCAR, José de. Sessão de I3 jul. I87I. Annaes da Camara dos Deputados, apud CHALHOUB, Sidney. Machado

de Assis, historiador, op. cit., p. 198 (grifos meus).

72 ASSIS, Machado de. Yaya Garcia, op. cit., p. 9. 
Jorge, de que tanto se falara antes da morte de Luiz Garcia, lhe serve de indício para concluir "que aquela carta era alguma cousa mais do que um recado sem consequência"73.

Mais: as palavras que ele escolhe para explicar à moça sua desobediência "Raimundo não achou bonito que Iaiá escrevesse àquele homem, que não é seu pai nem seu noivo"74 - têm forte ressonância no interior da tradição social e literária dentro da qual Machado está trabalhando. Como vimos em Macedo e Alencar, o risco que a carta traz é exatamente o de driblar o controle da autoridade paterna, que é, ao fim e ao cabo, a responsável pela autorização do casamento das mulheres, colocando os interesses da família como um todo sobre os interesses individuais (de tipos sociais incapazes de tomar decisões criteriosas). Um risco, lembre-se, que só pode ser levado adiante por uma figura que é, ela mesma, outro tipo incapaz, o escravo, o qual, ao servir como transição entre a casa e a rua, não teria a real dimensão das suas ações. Daí que, nas cenas que analisamos, o tropo da carta sinalize um perigo para a família e precise ser debelado pelas figuras de autoridade: um velho roceiro em Macedo; um homem doutor em Alencar. Dois personagens masculinos, brancos, senhores e proprietários; em suma, o ponto mais alto da hierarquia social do século XIX. Embora seja com esse universo simbólico que Raimundo esteja lidando (uma moça só deve escrever a seu pai e a seu noivo, e a este quando tiver o consentimento daquele), ele apresenta certas fraturas. Toda a crise desencadeada por Iaiá depois da morte do pai é contornada, primeiro, por Estela, uma mulher do estrato médio da sociedade, outrora agregada, e, depois, por Raimundo, um negro alforriado. São esses dois tipos, sem prestígio na hierarquia senhorial brasileira oitocentista, os responsáveis pela manutenção da ordem, sem a qual o enredo de casamento não pode chegar a um desfecho que possibilite a união dos apaixonados.

\section{SOBRE O AUTOR}

RODRIGO CERQUEIRA é professor adjunto

de Literatura Brasileira da Universidade

Federal de São Paulo (Unifesp).

E-mail: drigocerqueira@gmail.com

\section{REFERÊNCIAS BIBLIOGRÁFICAS}

ALENCAR, José de. O demônio familiar. Rio de Janeiro: Typ. Soares \& Irmão, I858. . Ao imperador: novas cartas políticas de Erasmo. Rio de Janeiro: Typ. de Pinheiro, I867.

73 Ibidem, p. 299.

74 Ibidem, p. 3I5. 
. O systema representativo. Rio de Janeiro: B. L. Garnier, I868.

ALONSO, Angela. Ideias em movimento: a geração de I870 na crise do Brasil-Império. São Paulo: Paz e Terra, 2002.

ASSIS, Machado de. Semana literária I. Diário do Rio de Janeiro, 6 mar., I866, p. I. . Yaya Garcia. Rio de Janeiro: Typ. do Cruzeiro, I878.

BOONE, Josehp Allen. Tradition counter tradition: love and the form of fiction. Chicago: The University of Chicago Press, I987.

BOSI, Alfredo. Dialética da colonização. São Paulo: Cia. das Letras, I992.

CANDIDO, Antonio. Crítica e sociologia. In: . Literatura e sociedade. 9. ed. Rio de Janeiro: Ouro sobre Azul, 2006, p. I3-25.

CHALHOUB, Sidney. Machado de Assis, historiador. São Paulo: Cia. das Letras, 2003.

DARNTON, Robert. O grande massacre de gatos e outros episódios da história cultural francesa. 2. ed. Rio de Janeiro: Graal, I986.

DIAS, Maria Odila. Quotidiano e poder em São Paulo no século XIX. São Paulo: Brasiliense, I984.

Prefácio. In: MARINS, Paulo César Garcez. Através da rótula: sociedade e arquitetura no Brasil, séculos XVII a XX. São Paulo: Humanitas, 200I, p. 9-I9.

FREYRE, Gilberto. Sobrados e mucambos: decadência do patriarcado e desenvolvimento do urbano. I6. ed. São Paulo: Global, 2006.

GAMA, Miguel do Sacramento Lopes. O carapuceiro: crônicas de costumes. São Paulo: Cia. das Letras, I996.

GRAHAM, Sandra Lauderdale. House and street: the domestic world of servants and masters in nineteenth-century Rio de Janeiro. Cambridge: Cambridge UP, I988.

.Caetana diz não: história de mulheres da sociedade escravista brasileira. São Paulo: Cia. das Letras, 2005.

MACEDO, Joaquim Manuel de. A moreninha. 9. ed. Rio de Janeiro: Garnier, s.d. [I844]. Rosa. Rio de Janeiro: H. Garnier, 2 t., s.d. [I849].

Memórias da Rua do Ouvidor. Rio de Janeiro: Typ. Perseverança, I878, p. I35.

MARINS, Paulo César Garcez. Através da rótula: sociedade e arquitetura no Brasil, séculos XVII a XX. São Paulo: Humanitas, 200I.

. Através da rótula: sobre mediações entre casas e ruas. Cadernos CERU, São Paulo, série 2, n. 8, p. 5I-57, I997. Disponível em: 〈http://www.revistas.usp.br/ceru/article/view/74974〉. Acesso em: 26 jul. 2016. NEEDELL, Jeffrey. The party of order: the conservatives, the state, and slavery in Brazilian monarchy, I83I-I87I. Stanford: Stanford UP, 2006.

PRADO, Décio de Almeida. Os demônios familiares de Alencar. Revista do IEB, São Paulo, n. I5, I974, p. 27-57. Disponível em <http://dx.doi.org/Io.II606/issn.23I6-90IX.voir5p27-57>. Acesso em: 3 mar. 2013. RIZZO, Ricardo Martins. Entre deliberação e hierarquia: uma leitura da teoria política de José de Alencar (I929-I877). Dissertação (Mestrado em Ciência Política). Faculdade de Filosofia, Letras e Ciências Humanas, Universidade de São Paulo, São Paulo, 2007.

WILLIAMS, Raymond. Marxism and literature. Oxford: Oxford UP, I977. 